\title{
The Influence of Foliage Plants on Psychological and Physiological Responses
}

\author{
Yoshihito Kurazumi 1', Emi Kondo², Kenta Fukagawa3 ${ }^{3}$, Reiko Hashimoto', Agnes Nyilas', \\ Tomonori Sakoi ${ }^{4}$, Tadahiro Tsuchikawa ${ }^{5}$
}

${ }^{1}$ School of Life Studies, Sugiyama Jogakuen University, Nagoya, Japan

${ }^{2}$ Department of Architecture, Ariake National College of Technology, Omuta, Japan

${ }^{3}$ Department of Architecture, Kyushu Sangyo University, Fukuoka, Japan

${ }^{4}$ Academic Assembly, Institute of Textile Science and Technology, Shinshu University, Ueda, Japan

${ }^{5}$ School of Human Science \& Environment, University of Hyogo, Himeji, Japan

Email: *kurazumi@sugiyama-u.ac.jp

How to cite this paper: Kurazumil, Y., Kondo, E., Fukagawa, K., Hashimoto, R., Nyilas, A., Sakoi, T. and Tsuchikawa, T. (2017) The Influence of Foliage Plants on Psychological and Physiological Responses. Health, 9, 601-621.

https://doi.org/10.4236/health.2017.94043

Received: March 1, 2017

Accepted: April 9, 2017

Published: April 12, 2017

Copyright (c) 2017 by authors and Scientific Research Publishing Inc. This work is licensed under the Creative Commons Attribution International License (CC BY 4.0).

http://creativecommons.org/licenses/by/4.0/

\section{cc) (i) Open Access}

\begin{abstract}
This research aims to clarify the significance of incorporating visual stimulation, in the form of foliage plants, into office desktop spaces. The experiments were conducted in a thermal environment with a temperature range that was slightly uncomfortable. The indoor thermal environment evaluation index ETF was used to measure the effects that brain stimulation of foliage plants have on comprehensive thermal senses. We focus on visual stimulation with foliage plants, and quantitatively measure shifts in thermal senses that affect the body. Thermal environment conditions were established with air temperature in three stages $\left(25^{\circ} \mathrm{C}, 28^{\circ} \mathrm{C}\right.$ and $\left.31^{\circ} \mathrm{C}\right)$ and the atmosphere was kept homogeneous with wall surface temperature equal to air temperature. The visual stimulations consisted of seven types of office desk image: benjamin, pothos, oxycardium, baby tears, moss ball, cacti, and no plant. At around $27^{\circ} \mathrm{C}$ to $29^{\circ} \mathrm{C}$ ETF, improvements in thermal sensation, as measured by thermal sensation statements, were shown to have resulted from visual stimulation benefits. Also, at around $26^{\circ} \mathrm{C}$ to $29^{\circ} \mathrm{C}$ ETF, improvements in comfort were shown, due to visual stimulation benefits as well, in subjects' comfortable-sensation statements. This benefit was significant when a foliage plant's green coverage ratio came between $0.75 \%$ and $4.67 \%$, the range which does not create an overwhelming feeling from the foliage plant.
\end{abstract}

\section{Keywords}

ETF, Foliage Plant, Thermal Sensation, Thermal Comfort, Visual Stimuli

\section{Introduction}

The comprehensive thermal senses that people experience are not expressed 
simply by the thermal balance between the physical environment and the body. Effects of visual and auditory stimulation create differences in thermal sense, due to high-level brain processes. In air-conditioned spaces indoors, as opposed to extreme temperature settings outdoors, one can create temperature environments that are slightly hot or slightly cold, which people will experience as slightly uncomfortable.

It is difficult to control auditory stimulation with any precision, but visual stimulation can be selectively controlled. Therefore, if one can quantitatively clarify the benefits of using visual stimulation to relieve the minor discomfort of a thermal environment that is set at a particular temperature, it could be very cost-effective for the running costs of air-conditioning equipment.

According to the Biophilia Hypothesis advanced by Wilson [1], humans have adapted and evolved to have positive emotional and behavioral responses to organisms that provide benefits for survival. Those responses remain in humans today [2]. That is, in the process of human evolution, humans developed positive emotions toward environments that had benefits for survival, and today still have a mental desire to be in such environments. In contrast, humans emotionally dislike environments that are disadvantageous for survival, and have a mental desire to avoid them. Such emotions occur quickly and automatically, the result of mechanisms obtained in the process of evolution. This concept is based on the theory of Zajonc [3] that emotional response occurs before awareness. If a person comes into contact with an environment that is beneficial for survival, it provides not simply an absence of stress, but also beneficial relaxation and recovery from fatigue.

Ulrich [4] posits that certain phenomena of nature have healing benefits for humans. For patients after surgery, this affirms the benefits of the view outside the hospital room. With patients who had just undergone surgery in the same hospital room in the same hospital, Ulrich had one group view trees from the hospital room, and another group able only to see the wall of a building. Then Ulrich compared the number of hospitalization days after surgery, the number of complaints about pain and dissatisfaction, and the quantity of pain relief medicine required. In all aspects, patients in the group that could see trees tended to have better recoveries than those who could not see trees.

Non-heat factors such as vision and hearing are also shown to affect sensation and comfort for the thermal senses [5] [6] [7] [8] [9]. Experimental laboratory research on environmental factors and body responses has found that thermal sensation and thermal comfort are affected by visual and auditory factors such as greenery and water. However, these studies generally only examined the burden with or without stimulation, but did not evaluate according to the sensational and physiological temperature. That is, quantitative research was not done.

Kurazumi et al. [10] used the outdoor thermal environment evaluation index ETFe [11], and found that thermal environment stimulation increases the body's tolerance limit for such stimulation in outdoor spaces more than it does in 
summer indoor spaces. Visual stimulation by a natural view composed of greenery such as trees creates a neutral thermal sensation that is approximately $3.5^{\circ} \mathrm{C}$ lower than visual stimulation by man-made views consisting of buildings and asphalt pavement; they thus found that greenery has benefits for relieving heat sensation. Natural landscape observation points thus have a smaller reduction in thermal comfort than other landscape observation points, even when there is a rise in mean skin temperature, a physiological quantity. Spaces containing natural elements such as trees are found to be more effective in improving a sense of comfort than spaces with views of cities or other spaces with inorganic man-made elements of concrete, metal, etc.

Energy conservation propaganda in Japan encourages people to set the air conditioning at $28^{\circ} \mathrm{C}$ during the summer. This can have large benefits for private building spaces that pay the expense of air conditioning. On the other hand, this can prove less beneficial in public building spaces, where it can cause dissatisfaction.

An air temperature of $28^{\circ} \mathrm{C}$ is a thermal environment that maintains a naked, seated, resting human body in a neutral status. In private building spaces where people can adjust their clothing and posture, they can use behavioral thermoregulation to adjust their sensational and physiological temperature based on heat exchange between the body and the environment.

However, in public building spaces where the thermoregulation behaviors described above are difficult, this temperature setting can make it impossible to maintain a neutral thermal status, and can affect concentration and harm health. Room temperature set at $28^{\circ} \mathrm{C}$ is not a thermal environment conducive to concentration and performance of light tasks [12]. Setting the air conditioning at $28^{\circ} \mathrm{C}$ to create an energy-conserving environment and thus benefit the global environment is admirable, but other cost-effective environmental controls are needed to offset the unforeseen costs.

Also, from an energy conservation viewpoint, there are hopes that the Task and Ambient Air Conditioning System is a next-generation innovation that can obtain both comfort and energy conservation. The fields of work people are performing (Task) and the spaces around them (Ambient) are divided, and cooling and heating is concentrated only where needed, for efficient and comfortable control. By relieving some of the subtle problems that air conditioning creates in the ambient space, this can work to reduce costs by energy conservation. However, office spaces with frequent entry and exit, among other variables, can create large temperature variation. For a global warming countermeasure, Japan's Ministry of the Environment created a campaign that calls on the people to make a "COOL CHOICE" [13].

To achieve the target of fiscal 2030 global warming gas emissions being $26 \%$ less than in fiscal 2013, "COOL CHOICE" is a national campaign that encourages various "clever choices" that contribute to global warming reduction, and indeed Japan leads the world in energy-conserving, low-carbon products, services, 
and behaviors. As one of various actions towards achieving a low-carbon society, it has been advocating "COOLBIZ" since summer 2015, so people can be comfortable in offices even with the air conditioning set at $28^{\circ} \mathrm{C}$. "COOLBIZ" calls for people to engage in behavioral thermoregulation by wearing clothing that feels comfortable at room temperature of $28^{\circ} \mathrm{C}$.

As noted above, setting the air temperature at $28^{\circ} \mathrm{C}$ is feasible in private spaces such as residences, where environmentally conscious behavior is possible, but it is undeniable that this can force people to endure discomfort in public work spaces like offices. Focusing on this point, Kurazumi et al. [14] took $28^{\circ} \mathrm{C}$ air-conditioning temperature as a reference point, and experimented on subjects in areas with an environmental range at temperatures that are slightly uncomfortable. They found that in such a range-higher than approximately $28^{\circ}$ to $29^{\circ} \mathrm{C}$ ETF indoor thermal environment evaluation index [15]-visual stimulation by natural-view elements consisting of greenery such as plants in outdoor space has the benefit of improving the thermal senses.

For visual stimulation, it was found that elements with less than a $70 \%$ green coverage ratio are suitable; this gives a sense of depth with three-dimensional plants, and a dynamic benefit is expected for thermal environment conditions. Even in air-conditioned spaces that are slightly hot and have a high possibility of forcing people to endure, brain stimulation by greenery such as plants was found to benefit comprehensive thermal senses, and actively incorporating visual stimulation by the green of plants in indoor space was found to be significant. This suggests that visual stimulation of natural-view elements by greenery such as plants can be used to create environmentally friendly energy-conserving spaces.

Therefore, in air-conditioned spaces such as offices, instead of extreme temperature settings, these become thermal environments that are slightly hot and uncomfortable. Applying audio stimulation is not realistic in office work spaces, but foliage plants can be placed on desktops, and such visual stimulation can be expected to bring beneficial relief to thermal senses. If foliage plants placed on desktops are shown to improve thermal senses, then one can conjecture that air-conditioned spaces that would otherwise seem to be too warm can be shifted to become more comfortable.

Thus this research aims to use the $28^{\circ} \mathrm{C}$ air-conditioned temperature as a reference point, experiment on subjects in a thermal environment with a temperature range that is slightly uncomfortable, and use the ETF indoor thermal environment evaluation index to clarify the effects that brain stimulation by the visual presence of foliage plants has on comprehensive thermal senses. We thus seek to clarify the significance of actively incorporating greenery of foliage plants as visual stimulation in office desktop spaces.

We focus on visual stimulation with foliage plants, and quantitatively measure shifts in thermal senses that affect the body. We thereby study effective actions for summer air conditioning set at $28^{\circ} \mathrm{C}$. If visual stimulation can be clearly shown to benefit thermal senses by high-level brain processes, then environmentally friendly energy-saving spaces can be created. 


\section{Execution Plan}

\subsection{ETF}

The conduction-corrected modified effective temperature $(E T F)$ is indoor thermal environment evaluation index. The ETF was developed by Kurazumi et al. [15]. The team performed demonstration experiments to clarify the relationship between ETF and the body's physiological and psychological effects, and found it to be effective as an indoor environment evaluation index [16]. The ETF can convert into individual thermal environment elements the effects of posture differences, air velocity, long-wavelength thermal radiation, surface temperature of material touching the body, and humidity.

The effects of these five environmental factors that contribute to the body's heat exchange can be expressed by newly defined thermal environment evaluation indices: Thermal Velocity Field, including effects of convective heat transfer area $\left(T V F_{h t a}\right)$ for air velocity; long-wavelength Effective Radiative Field, including the effects of radiant heat transfer area $\left(E R F_{h t a}\right)$ for long-wavelength thermal radiation; Effective Conduction Field, including effects of conductive heat transfer area $\left(E C F_{h t a}\right)$ for surface temperature of material touching the body; and Effective Humidity Field at temperature $E T F\left(E H F_{E T F}\right)$ for humidity. Each factor individually converted into temperature can be added to air temperature, and comprehensive effects on sensational and physiological temperature and effects of individual thermal environment factors can be quantified on the same evaluation axis. Heat exchange is standardized by all the body surface area of the human body.

$$
\begin{gathered}
E T F=T_{a}+\frac{T V F_{h t a}}{h_{f}}+\frac{E R F_{h t a}}{h_{f}}+\frac{E C F_{h t a}}{h_{f}}+\frac{E H F_{E T F}}{h_{f}} \\
T V F_{h t a}=\left(h_{o} \text { fcl Fclo } f_{\text {conv }}-h_{c} f c l F c l f_{\text {conv }}\right)\left(T_{s}-T_{a}\right) \\
E R F_{\text {hta }}=h_{r} \text { fcl Fcl } f_{\text {rad }}\left(T_{r}-T_{a}\right) \\
E C F_{h t a}=h_{d} \text { Fcld } f_{\text {cond }}\left(T_{f}-T_{a}\right) \\
E H F_{E T F}=L w h_{c} \text { fcl Fpcl }\left(p_{a}-0.5 p_{E T F} *\right) \\
h_{f}=h_{o} f c l \text { Fclo } f_{\text {conv }}+h_{r} f c l \text { Fcl } f_{\text {rad }}+h_{d} \text { Fcld } f_{\text {cond }}
\end{gathered}
$$

where

ETF: conduction-corrected modified effective temperature [K];

$T_{a}$ : air temperature $[\mathrm{K}]$;

$T V F_{h t a}:$ convective heat transfer area of the combined thermal velocity field $\left[\mathrm{W} / \mathrm{m}^{2}\right]$;

$E R F_{\text {hta: }}$ radiant heat transfer area combined with the effective radiation field for thermal radiation $\left[\mathrm{W} / \mathrm{m}^{2}\right]$;

$E C F_{h t a}$ : conductive heat transfer area combined with effective conduction field $\left[\mathrm{W} / \mathrm{m}^{2}\right]$;

$E H F_{E T F}$ : effective humid field at ETF temperature $\left[\mathrm{W} / \mathrm{m}^{2}\right]$;

$f c l$ effective surface area factor of clothing [-]; 
$f_{\text {conv }}:$ convective heat transfer area factor [-];

$f_{\text {cond: }}$ conductive heat transfer area factor [-];

$f_{\text {radi }}$ : radiant heat transfer area factor [-];

Fcl: thermal efficiency factor of clothing in the exposed airflow area [-];

Fcld: thermal efficiency factor of clothing in the heat conduction area [-];

Fclo: thermal efficiency factor of clothing under standard conditions [-];

Fpcl: permeation efficiency factor of clothing [-];

$h_{\dot{c}}$ convective heat transfer coefficient $\left[\mathrm{W} / \mathrm{m}^{2} \mathrm{~K}\right]$;

$h_{r}$ : radiant heat transfer coefficient $\left[\mathrm{W} / \mathrm{m}^{2} \mathrm{~K}\right]$;

$h_{\dot{d}}$ : resultant heat conductance $\left[\mathrm{W} / \mathrm{m}^{2} \mathrm{~K}\right]$;

$h_{\dot{f}}$ sensible heat transfer coefficient $\left[\mathrm{W} / \mathrm{m}^{2} \mathrm{~K}\right]$;

$h_{o}$ : convective heat transfer coefficient under standard conditions $\left[\mathrm{W} / \mathrm{m}^{2} \mathrm{~K}\right]$;

$L$ : Lewis relation coefficient $[\mathrm{K} / \mathrm{kPa}]$;

$p_{a}$ : water vapor pressure at outdoor air temperature $[\mathrm{kPa}]$;

$p_{E T F}{ }^{\star}$ : saturated water vapor pressure at conduction-corrected modified effective temperature $[\mathrm{kPa}]$;

$T_{s}$ : convection-corrected mean skin temperature $[\mathrm{K}]$;

$T_{\dot{F}}$ surface temperature of the contacted material $[\mathrm{K}]$;

$\mathrm{T}_{\mathrm{r}}$ : mean radiant temperature for long-wave radiation $[\mathrm{K}]$;

w. skin wettedness [-].

\subsection{Measurement Steps}

The experiments were carried out from July to August in 2015 and 2016. The experiment used the experiment room shown in Figure 1. Due to the necessity of minimizing effects on visual stimulation, colors in the experiment room are white. The experiment was performed by projecting visual stimulating images

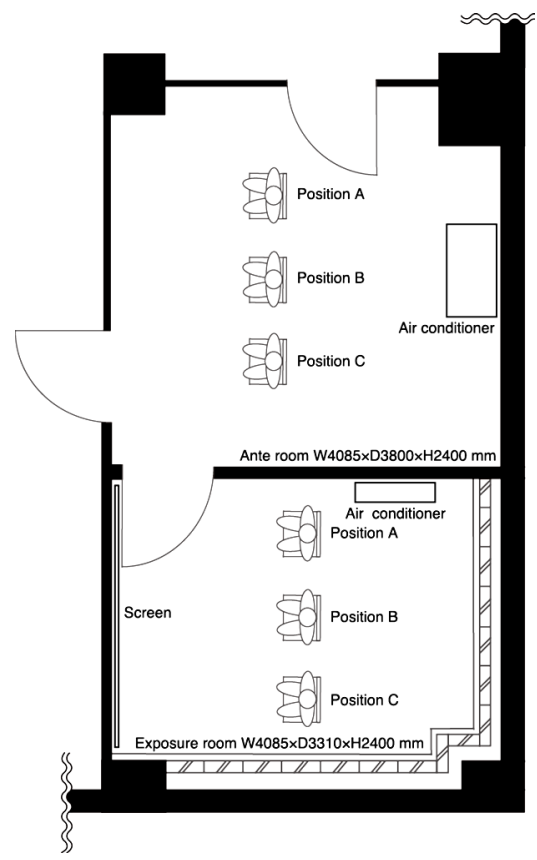

Figure 1. Plan of experimental set up where subjects are exposed to thermal conditions. 
onto a screen installed in the environment experiment room. The thermal environment conditions set were in three stages $-25^{\circ} \mathrm{C}, 28^{\circ} \mathrm{C}$, and $31^{\circ} \mathrm{C}$ air temperature-with the homogeneous condition of the wall surface temperature the same as the air temperature. In all conditions, air velocity (slow air flow of 0.2 $\mathrm{m} / \mathrm{s}$ or less) and relative humidity $(60 \% \mathrm{RH})$ were the same.

Due to the necessity of minimizing effects on visual stimulation and the necessity of clarifying body shape effects, the subjects were dressed lightly in white clothing. Subjects were in sitting postures during the experiment, and subjects' work status was at rest.

Each subject maintained a resting status in a sitting posture for at least 45 minutes in a controlled, tranquil anteroom, with wall temperature equal to air temperature, and with air temperature and relative humidity the same as the initial environment condition settings. After that, the subject quickly moved into the experiment room, and was exposed for at least 15 minutes to the thermal environment condition settings. Considering that the thermal environment's effects on the human body due to the environment history ended, and they adapt to the thermal environment condition settings, we set at least 60 minutes of exposure time for adaptation to thermal environment conditions. After that, the subject maintained the set posture at the exposure location in a status maintaining the thermal environment condition settings, and the experiment that applied visual stimulation began.

There were six types containing foliage plants that were at most $0.3 \mathrm{~m}$ high and an additional condition type with $0 \%$ green coverage ratio as control stimulation and a visual stimulation of only the desk, for seven total types of desktop images. The green coverage ratio is the green area of foliage plants as a percentage of the visual stimulation image projected on a screen. Each visual stimulation was presented for 180 seconds, and each subject stated his or her psychological senses 30 seconds after each visual stimulation was presented. The visual stimulations were presented randomly.

\subsection{Visual Stimulation}

Kurazumi et al. [10] have shown that, in outdoor spaces, visual stimulation by a natural view consisting of greenery such as trees has benefits for sensation of warmth and thermal comfort, compared to visual stimulation by man-made views of buildings and asphalt pavement. The higher the solid-angle ratios of natural-view elements, the stronger their benefits. Kurazumi et al. [14] also found it valid that, in indoor spaces, visual stimulation from greenery gives a sense of depth of three-dimensional plants, and natural-view elements are expected to benefit thermal environment conditions dynamically. Such research uses high values for the green coverage ratio of visual stimulation in the field of vision. However, it is very difficult to bring many plants into a personal desktop space in an office. Also, in order to arrange the work environment, the plants must be a certain distance from the subject's vision.

Thus we selected foliage plants presented as visual stimulation with a maxi- 
mum $0.3 \mathrm{~m}$ height planted in pots, and varying green ratios. For the images presented as visual stimulation, we assumed a sitting office worker focusing on a foliage plant placed on a desktop surface that is $1.3 \mathrm{~m}$ ahead. The office desk is 0.7 $\mathrm{m}$ high. The visual axis of the office worker gazes at the foliage plant at a depression angle of $22.6^{\circ}$. Table 1 shows the visual stimulation.

For visual stimulation, we used six types of foliage plants (benjamin, pothos, oxycardium, baby tears, moss ball, and cacti), and the condition of no foliage plants in the visual stimulation, for a total of seven conditions of office desktop images. We used potted foliage plants approximately $10 \mathrm{~cm}$ in diameter. Figure 2 shows the foliage plants.
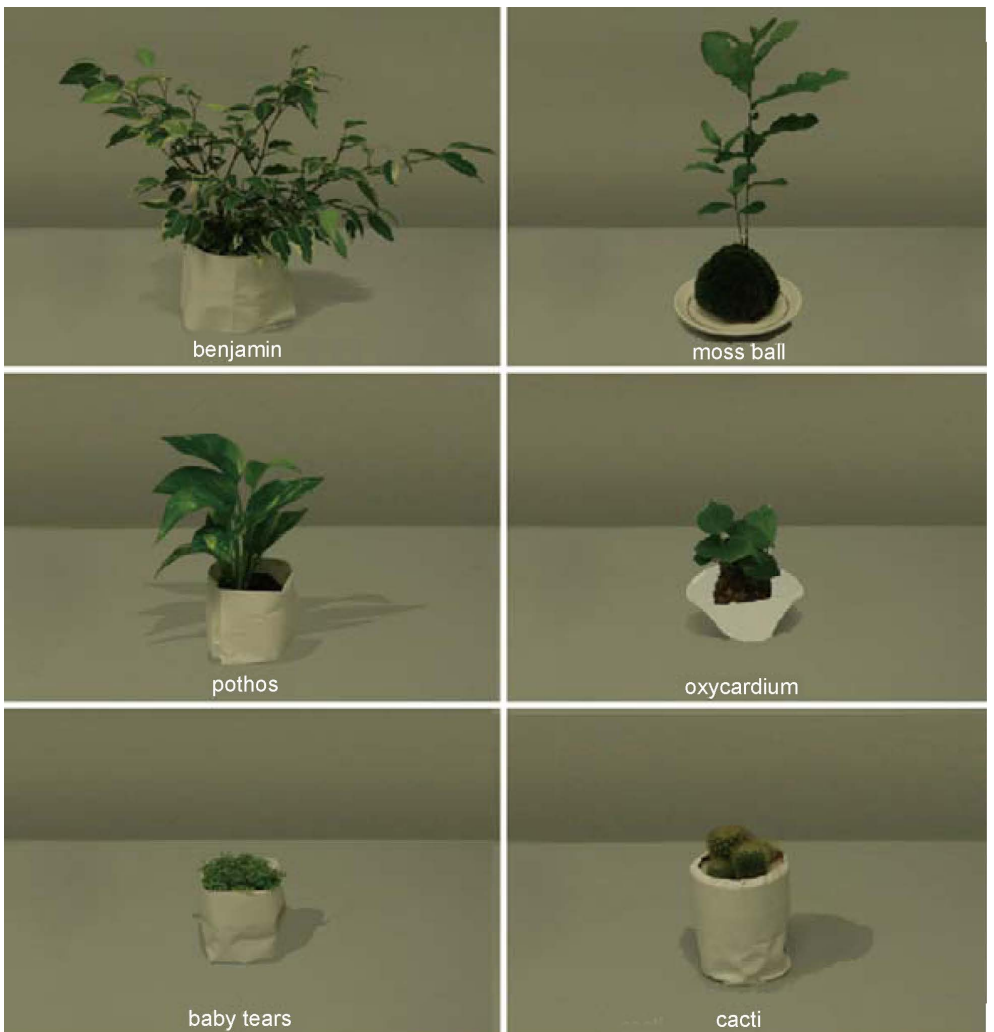

Figure 2. Foliage plants.

Table 1. Summary of visual stimuli.

\begin{tabular}{cc}
\hline Visual stimuli scene & Green factor \\
\hline baby tears & 0.39 \\
moss ball & 2.24 \\
benjamin & 4.67 \\
pothos & 1.41 \\
oxycardium & 0.75 \\
cacti & 0.27 \\
none foliage plant & 0.00
\end{tabular}

Green factor is green covering factor. Green covering factor is defined as the ratio of green surface areas to a picture area. 
For cacti, we used spherical golden barrel cacti: two of approximately $4 \mathrm{~cm}$ diameter, and two approximately $2 \mathrm{~cm}$ in diameter, grouped in a pot. The leaves of this species are gold color spines. These are the most popular cacti seen in gardens and such and have $0.27 \%$ green coverage ratio.

For the moss ball, we used an acorn tree approximately $20 \mathrm{~cm}$ high, with a small crown architecture spread packaged in a ball, its surface covered with Hypnaceae. Adding the thick growth of acorn tree leaf surfaces, it has a high green coverage ratio. This plant is suited for humid environments, and is used for bonsai. It has a $2.24 \%$ green coverage ratio.

For the benjamin, we used an approximately $30 \mathrm{~cm}$ high starlight plant with a large crown architecture spread. Dense leaves hang vertically and cover a large area. This is a popular foliage plant. It has a $4.67 \%$ green coverage ratio.

For baby tears, we used a mat form with the plant pot's soil surface covered by dense leaves. The leaves are very small, at approximately 2 to $3 \mathrm{~mm}$. This plant is suited for humid environments, and is also used for ground cover. It has a $0.39 \%$ green coverage ratio.

We used an approximately $20 \mathrm{~cm}$ high Pothos N'Joy for the pothos. Young leaf period plants are used as foliage plants, so it has a small crown architecture spread, but dense leaves. Its leaves are 4 to $7 \mathrm{~cm}$, green with white spots. It has a $1.41 \%$ green coverage ratio.

For oxycardium, we used approximately $15 \mathrm{~cm}$ high-straight-stalk standing plants: Philodendron Scandins and oxycardium. Its leaves are 3 to $5 \mathrm{~cm}$, eggshaped, glossy light green. It has a $0.75 \%$ green coverage ratio.

At $1.2 \mathrm{~m}$ eye height at the subject's position, the solid-angle ratio of visual stimulation when the center of the image is presented in the line of vision direction was 0.09 at Position A, 0.10 at Position B, and 0.09 at Position C. These were differences of 0.01 in the solid-angle ratio of visual stimulation at the subject's position, so these were not large differences.

\subsection{Experiment Subjects}

The subjects were volunteers. Based on the mean height and weight and the standard deviation of height and weight [17] [18], the subjects were selected. The subjects were twelve healthy young male and female university students. Table 2 shows the subjects' characteristics. The six young men had height of $174.9 \pm 5.8$ $\mathrm{cm}$ and weight of $62.8 \pm 6.3 \mathrm{~kg}$. The six young women had height of $157.1 \pm 5.4$ $\mathrm{cm}$ and weight of $55.3 \pm 9.3 \mathrm{~kg}$. None of the subjects had unusual physiques. These were standard subjects.

In accordance with the Declaration of Helsinki [20], the experiment was sufficiently explained to the subjects beforehand, and their consent was obtained for participation in the experiment.

\subsection{Execution Items}

For thermal environment conditions, we measured air temperature, humidity, air velocity, and wall surface temperature. For air temperature and humidity, we 
Table 2. Physical characteristics of subjects.

\begin{tabular}{cccccccc}
\hline Subject & Sex & Age & \multicolumn{2}{c}{ Height $[\mathrm{cm}]$ Weight $[\mathrm{kg}]$ B-area $\left[\mathrm{m}^{2}\right]$} & $\begin{array}{c}\text { Rohrer } \\
\text { Index }\end{array}$ & Native place \\
\hline OZ & Female & 21 & 163.4 & 54.3 & 1.58 & 124.5 & Aichi \\
UM & Female & 22 & 154.1 & 48.4 & 1.45 & 132.3 & Aichi \\
KA & Female & 22 & 161.8 & 45.9 & 1.47 & 108.4 & Aichi \\
TA & Female & 21 & 158.3 & 44.9 & 1.44 & 113.2 & Aichi \\
MO & Female & 21 & 147.1 & 41.0 & 1.32 & 128.8 & Shizuoka \\
AR & Female & 22 & 158.0 & 52.4 & 1.53 & 132.8 & Shizuoka \\
IW & Male & 22 & 163.3 & 51.4 & 1.55 & 117.8 & Fukuoka \\
UE & Male & 21 & 175.4 & 67.1 & 1.80 & 124.3 & Yamaguchi \\
UT & Male & 20 & 174.3 & 67.4 & 1.80 & 127.3 & Shimane \\
OT & Male & 20 & 180.1 & 69.6 & 1.86 & 119.1 & Fukuoka \\
KO & Male & 21 & 181.6 & 57.9 & 1.75 & 96.7 & Fukuoka \\
TN & Male & 21 & 174.4 & 63.5 & 1.76 & 119.7 & Kagoshima \\
\hline
\end{tabular}

B-area is the calculated body surface area by Kurazumi's formula [19]. S $=100.315$ W0.383 H0.693 $\times 10^{-4}$ (Kurazumi et al., 1994). S: Body surface area $\left[\mathrm{m}^{2}\right]$, W: Weight $[\mathrm{kg}], \mathrm{H}$ : Height $[\mathrm{cm}]$. Native place is life region from birth to 2.5 years old time.

measured at $0.6 \mathrm{~m}$ height above the floor using a small humidity data logger (ESPEC MIC: RS-13, temperature measurement range $0^{\circ} \mathrm{C}-50^{\circ} \mathrm{C}$, precision $0.3^{\circ} \mathrm{C}$, humidity measurement range $10 \%-95 \%$, precision $5 \%$ ). We measured the air velocity at $0.6 \mathrm{~m}$ height above the floor with a hot-ball-type omnidirectional anemometer (Kanomax Japan: 6533, measurement range 0.05 to $5.00 \mathrm{~m} / \mathrm{s}$, precision $2 \%$ ). The surface temperature of each surface of the room was measured with a $0.3 \mathrm{~mm} \varphi$ type $\mathrm{T}$ thermocouple.

For the solid angle of visual stimulation, we measured by the photo-taking method, using an equisolid angle fisheye projection-type lens (Olympus: Fisheye Zuiko $8 \mathrm{~mm} \mathrm{f/2.8)}$ ) and $35 \mathrm{~mm}$ digital single-lens reflex camera (Canon: EOS 5D) to take fisheye photos in the line of direction of the image presentation center, with subject position at $1.2 \mathrm{~m}$ above the floor, assuming a sitting-position eye height.

For physiological conditions of the body, we measured skin temperature by a thermistor thermometer (Nikkiso-Therm N542R data logger, measurement range $-50^{\circ} \mathrm{C}$ to $230^{\circ} \mathrm{C}$, precision $0.01^{\circ} \mathrm{C}$, and a Nikkiso-Therm Surface type probe for body surfaces: ITP8391). We measured skin temperature in eight places: head, trunk, arm, hand, thigh, lower leg, foot, and foot sole.

The female subjects wore light clothing: only a short-sleeved shirt, short pants, panties, and bra-camisole. The male subjects also wore light clothing: a shortsleeved shirt, knee-length underpants, and pants. Table 3 shows the clothing conditions. It was difficult to have them wear uniform panties, pants, and bracamisole, so the subjects brought these. We used the formula of Hanada et al. [21] [22] to calculate clo value from clothing weight. 
Table 3. Clothing ensembles of subjects.

\begin{tabular}{cccc}
\hline Subject & Description & Material [\%] & Weight [g] \\
\hline Male & Pants & - & $52-70$ \\
& Short-sleeved shirt & Cotton & $114-118$ \\
& Knee-length underpants & Cotton & 84 \\
Female & Panties & - & 20 \\
& Bra-camisole & - & 110 \\
& Short-sleeved shirt & Cotton & $114-118$ \\
& Short pants & Cotton 98\%, PU 2\% & 84 \\
\hline
\end{tabular}

$\mathrm{PU}$ is polyurethane.

This research measured psychological reactions 30 seconds after visual stimulation was presented, by a discrete grade scale of thermal sensation (seven stages), cool/warm sensation (seven stages) and thermal comfort (seven stages) as psychological conditions of the body.

Thermal sensation was given the end points of "cold" or "hot", cool/warm sensation was "cool" or "warm", and thermal comfort was "uncomfortable" or "comfortable". For each, the "cold", "cool", and "uncomfortable" endpoints were recorded as -3 , while the "hot", "warm", and "comfortable" endpoints counted as 3; numbers were allocated in equal intervals in between.

ETF [15] is an indoor thermal environment evaluation index based on heat exchange between the environment and the human body. Therefore, in mean skin temperature used in calculating heat exchange of the human body, we used a weighting coefficient which takes into account convective heat transfer area [23]. In calculation of mean skin temperature using physiological reactions of the human body, we used a weighting coefficient which takes into account heat conduction [24]. In calculating the total surface area of the human body, we used Kurazumi's formula [19]. For the convective heat transfer area factor, radiant heat transfer area factor, and conductive heat transfer area factor of the human body, we used the values of Kurazumi et al. [25]. For the configuration factor of the human body in a sitting posture, we used values of Tsuchikawa et al. [26]. For the radiant heat transfer coefficient and convective heat transfer coefficient of the human body, we used values of Kurazumi et al. [27]. For emissivity of the human body, we used 0.98 , obtained by the reflection ratio of skin at electromagnetic waves of $3 \mu \mathrm{m}$ or greater wavelength by Hendler et al. [28]. For calculation of latent heat loss of the human body, one can obtain the moisture heat loss by multiplying the weight reduction amount by the latent heat of vaporization.

However, using an experimental method that can only measure body weight immediately before and immediately after the start of exposure to thermal environment conditions, one cannot calculate the latent heat loss of the human body in each visual stimulation condition. Therefore, for skin wettedness, we used values calculated by the behavioral thermoregulation model of Kurazumi et al. 
[29]. By actual measurements of thermal environment elements, and from the body's skin temperature and clothing amount, we calculated the ETF indoor thermal environment evaluation index proposed and verified by Kurazumi et al. [15] [16].

As explanatory variables of thermal senses, environmental stimulations that directly affect thermal senses, such as air temperature, humidity, air velocity, long-wavelength thermal radiation, and surface temperature of material touching the body, greatly affect physiological and psychological reactions of the human body. On the other hand, environmental stimulation that indirectly affects thermal senses, such as visual stimulation, may not greatly contribute to the body's physiological and psychological reactions. In particular, environmental stimulation that indirectly affects thermal senses, such as visual stimulation, is expressed as a shift in comprehensive thermal senses by high-level brain processes.

In indoor air-conditioned spaces, instead of extreme temperature settings, thermal environments are slightly uncomfortable (slightly hot or slightly cold). In this research, considering the great noise and likelihood of variability in physiological reactions of the human body in indoor environments, we investigated with significance probability at $20 \%$ as a standard for comparison of explanatory variables to derive results of regression analysis, which would be more useful in practice. For statistical analysis, we used JMP12.2.0 (SAS Institute Japan).

\section{Thermal Environment Measurement Results}

Air temperature measurement results were at most $2.1^{\circ} \mathrm{C}$ higher than the value set; the temperature fluctuated within $\pm 1.1^{\circ} \mathrm{C}$. Wall surface temperature measurement results were at most $1.5^{\circ} \mathrm{C}$ higher than the value set; fluctuation there was within $\pm 0.4^{\circ} \mathrm{C}$. Relative humidity measurement results were at most $1.3 \%$ higher than the value set; that variable fluctuated within $\pm 4.3 \%$. Air temperature fluctuated a little more, but standard deviation was within $1.1^{\circ} \mathrm{C}$. Air velocity was measured in advance at $0.2 \mathrm{~m} / \mathrm{s}$ or less. These conditions were almost stable through all the experiments.

As described above, variables in the physical-environment that directly stimulate the thermal senses, such as air temperature, humidity, air velocity, long-wavelength thermal radiation, and surface temperature of material touching the body, greatly affect physiological and psychological reactions of the human body. Therefore, in the consideration section below, based on heat exchange between the human body and the environment, we investigated the effects of the ETF indoor thermal environment evaluation index [15] on the human body.

\section{Discussion}

\subsection{ETF and Mean Skin Temperature}

Figure 3 shows the relationship between ETF and mean skin temperature. It 


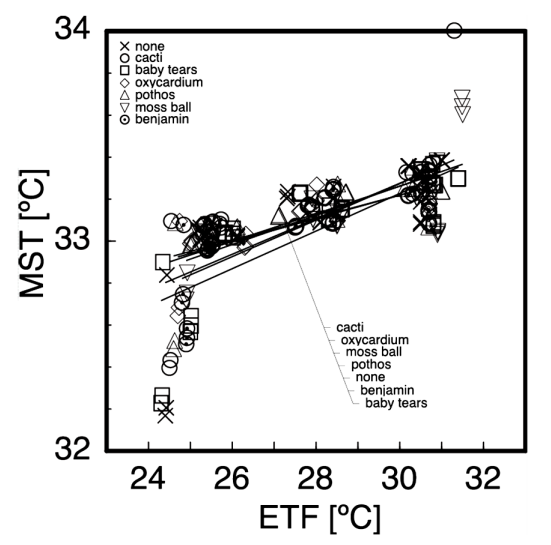

Figure 3. Relation between ETF and mean skin temperature.

shows that, at higher ETF, mean skin temperature also tends to be higher. Focusing on almost the same ETF stage, compared to when ETF is around $28^{\circ} \mathrm{C}$, dispersion is a little greater when ETF is around $25^{\circ} \mathrm{C}$.

Focusing on the regression line, mean skin temperatures were slightly higher where cacti, moss ball, pothos, and oxycardium were used. On the other hand, mean skin temperature was slightly lower with baby tears. However, those differences are within the level of measurement error and therefore not considered significant.

The result of investigation of parallelism of regression was $\mathrm{p}>0.05(\mathrm{~F}=1.83$, $\mathrm{p}=0.09$ ); the regression line did not show significant differences in parallelism. The result of investigation of homogeneity of regression line was $\mathrm{p}>0.05(\mathrm{~F}=$ $0.37, \mathrm{p}=0.90$ ); the regression line did not show significant differences in homogeneity. We performed multiple comparison by Tukey-Kramer HSD; this was $p>0.05$ between the condition of foliage plants not in visual stimulation, against conditions with foliage plants added, showing no significant difference due to visual stimulation. Therefore, in the range of ETF results of this research, as Kurazumi et al. [14] indicated, foliage plants as visual stimulation do not seem to affect mean skin temperature significantly.

\subsection{ETF and Thermal Sensation Statements}

Figure 4 shows the relationship between ETF and thermal sensation statements. Thermal sensation statements were greatly distributed. However, looking at the distribution of thermal sensation statements, we found that, as ETF becomes higher, thermal senses statements also tend to be higher on the hot side. Thermal sensation statements are in a discrete grade scale, so some thermal sensation statements are the same grade; many thermal sensation statements are concentrated at " -1 " for a $25^{\circ} \mathrm{C}$ thermal environment condition setting, " 0 " for $28^{\circ} \mathrm{C}$, and " 1 " for $31^{\circ} \mathrm{C}$.

Focusing on the regression line, when thermal environment conditions are $25^{\circ} \mathrm{C}$ or $31^{\circ} \mathrm{C}$, large differences due to foliage plants are not found in thermal sensation statements. However, we found that when thermal environment conditions are $28^{\circ} \mathrm{C}$, the condition of no visual stimulation by foliage plants, and 


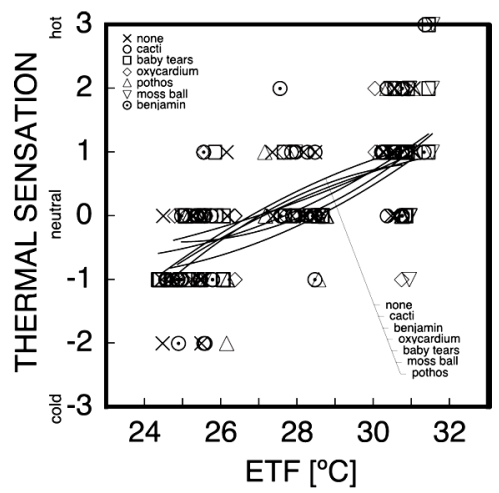

Figure 4. Relation between ETF and thermal sensation.

thermal sensation statements with cacti, tend to be on the hotter side compared to conditions which presented other foliage plants. We found that thermal sensation statements tend to be lower with pothos and moss ball. Thermal sensation statements with baby tears, oxycardium, and benjamin fall in the middle of the foliage plant groups described above.

Moss ball and baby tears are plants suited for wet conditions; they are utilized as ground cover, so they make people think of wetness. Baby tears does not have a high green coverage ratio, but it makes people think of wetness, which could have the effect of lowering thermal sensation statements.

Fukagawa et al. [9] found that, when a space has an open feeling, this helps relieve hotness. Also, Kurazumi et al. [14] found that a view of thickly growing plants with a high green coverage ratio increases the sense of being closed in, which weakens relief of hotness. Therefore, in a desktop space near the body, placement of a benjamin with a crown architecture that spreads may contribute to a sense of crowding, and weaken its relief of hotness.

At $25^{\circ} \mathrm{C}$ thermal environment conditions with statements around " -1 ," and at $31^{\circ} \mathrm{C}$ thermal environment conditions with statements around " 1 ," the regression lines cross, and the difference in benefits from visual stimulation by foliage plants may be tiny. Second-order regression coefficients of the regression equation are positive for pothos, moss ball, baby tears, and oxycardium, but they are negative for cacti, benjamin, and the condition where foliage plants are not present in visual stimulation. Therefore, under thermal environment conditions of approximately $27^{\circ} \mathrm{C}$ to $29^{\circ} \mathrm{C}$ ETF with neutral thermal sensation statements (i.e., neither hot nor cold), visual stimulation of foliage plants may have benefits.

We used a non-linear second-order regression model to check for homogeneity between the condition with no foliage plants in visual stimulation and conditions with foliage plants added. For moss ball against the condition of no foliage plants in visual stimulation, $\mathrm{p}<0.20$ for intercept and slope, showing significant differences. For baby tears against the condition of no foliage plants in visual stimulation, $\mathrm{p}<0.20$ for intercept and slope, showing significant differences. For pothos the condition of no foliage plants in visual stimulation, $p<0.20$ for intercept and slope, showing significant differences. The condition of no foliage plants in visual stimulation resulted in statements on the hottest side, so placing 
these foliage plants in the desktop space can be said to have a benefit that relieves hotness.

Matsubara et al. [6] showed that in a thermal environment condition that is a little on the uncomfortable side in an indoor space, the color benefit that lightens the thermal psychological burden is greater for cold colors when on the high temperature side, or warm colors when on the low temperature side.

Also, Kurazumi et al. [14] found that when ETF in an indoor space is higher than approximately $28^{\circ} \mathrm{C}$ to $29^{\circ} \mathrm{C}$, a range that is slightly uncomfortable, thermal senses are improved by the addition of plants. Kurazumi et al. [30] [14] found that people have basically low expectations for comfort in outdoor spaces, and thus even tolerate thermal environment conditions with a high ETFe outdoor thermal environment evaluation index [11]. Therefore, when ETF is approximately $27^{\circ} \mathrm{C}$ to $29^{\circ} \mathrm{C}$, which is a little lower than outdoor thermal environments, the benefits of visual stimulation may significantly affect the thermal sensation statements.

\subsection{ETF and Cool/Warm Sensation Statements}

Figure 5 shows the relationship between ETF and cool/warm sensation statements. As in the relationship between ETF and thermal sensation statements, cool/warm sensation statements have a wide distribution. However, we found that when ETF is higher, the distribution of cool/warm sensation statements also tend to be higher on the warm side. Warm sensation statements fall along a discrete grade scale, so some cool/warm sensation statements are at the same grade; many cool/warm sensation statements are concentrated at " -1 " or " 0 " for a $25^{\circ} \mathrm{C}$ thermal environment condition setting, " 0 " for $28^{\circ} \mathrm{C}$, and " 1 " for $31^{\circ} \mathrm{C}$.

Focusing on the regression line, when thermal environment conditions are $25^{\circ} \mathrm{C}$ or $31^{\circ} \mathrm{C}$, large differences due to foliage plants are not found in cool/warm sensation statements. However, we found that when thermal environment conditions are $28^{\circ} \mathrm{C}$, the condition of no visual stimulation by foliage plants, and $\mathrm{cool} /$ warm sensation statements with cacti, tend to be on the warmer side compared to conditions which presented other foliage plants. We found that cool/ warm sensation statements tend to be lower with pothos, oxycardium, moss ball,

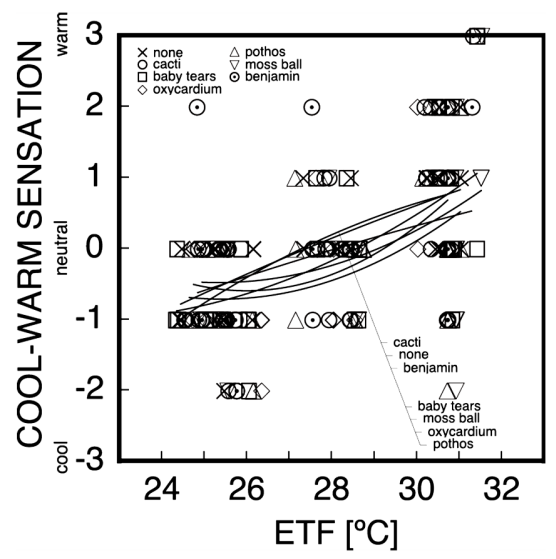

Figure 5. Relation between ETF and cool-warm sensation. 
and baby tears. Thermal comfort statements with benjamin are cool/warm sensation statements, which fall in the middle of the readings from the foliage plant groups described above.

As described for the relationship between ETF and thermal sensation statements, moss ball and baby tears have a dense shape of very small leaves; people look at a point on the green crown architecture, a shape which makes people think of wetness. Benjamin has a crown architecture that spreads in the desktop space near the body, which gives a sense of being closed in, which may weaken the relief of warm feelings [14].

At $25^{\circ}$ thermal environment conditions with statements that are approximately " -1 ", and at $31^{\circ}$ thermal environment conditions with statements that are approximately " 1 ", there may be tiny differences in benefits of visual stimulation by foliage plants. However, second-order regression coefficients of the regression equation are negative for pothos, oxycardium, moss ball, and baby tears, but they are positive for cacti, benjamin, and the condition of no plants. Therefore, under thermal environment conditions of approximately $27^{\circ} \mathrm{C}$ to $29^{\circ} \mathrm{C}$ ETF, which has neutral cool/warm sensation statements-neither cool nor warm - visual stimulation of foliage plants may have benefits.

We used a non-linear second-order regression model to check for homogeneity between the condition with no foliage plants in visual stimulation and conditions with foliage plants added. In all conditions with plants, compared to the condition without plants, $\mathrm{p}>0.20$ for intercept and slope, showing no significant differences.

In research by Matsubara et al. [6] and Shimada et al. [31] mainly on psychological evaluation, and by Kurazumi et al. [14] based on a comprehensive environment index for heat exchange, they found that benefits that improve nonspecific sensations according to independent heat exchange of cool/warm sensations are greater than those in thermal sensation, as measured by specific sensation-dependent heat exchange. But our research produced different results. Specific response can be defined as a response that depends on evaluating each type of environmental factor. Non-specific response is a response where combinations of all types of environmental factors are being evaluated. That is, non-specific response is the evaluation of impression of the space. The effects of visual stimulation in this research may have been affected by fondness for foliage plants. We found that high-level brain processes cause differences to occur in comprehensive thermal senses; this can be conjectured from the range of results in this research, but there is a need for further study.

\subsection{ETF and Thermal Comfort Statements}

Figure 6 shows the relationship between ETF and thermal comfort statements. As in the relationships between ETF and thermal sensation statements and cool/warm sensation statements, thermal comfort statements have a large distribution. Thermal comfort statements are measured on a discrete grade scale, so some thermal comfort statements are at the same level; many thermal comfort 


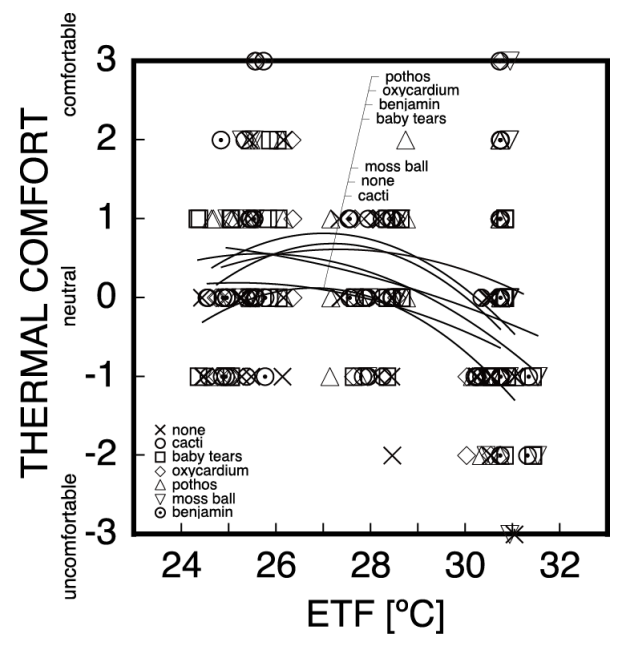

Figure 6. Relation between ETF and thermal comfort.

statements are concentrated at " -1 " or " 0 " for a $25^{\circ} \mathrm{C}$ thermal environment condition setting, " 0 " or " 1 " for $28^{\circ} \mathrm{C}$, and " -1 " for $31^{\circ} \mathrm{C}$. The tendency of thermal comfort statements indicates that the $26^{\circ} \mathrm{C}$ to $29^{\circ} \mathrm{C}$ ETF range may be the most comfortable thermal environment.

Focusing on the regression line in the range of $26^{\circ} \mathrm{C}$ to $29^{\circ} \mathrm{C} \mathrm{ETF}$, thermal comfort statements tend to be low with cacti or the condition with no foliage plants in visual stimulation. Thermal comfort statements tend to be high with pothos, oxycardium, or benjamin. Thermal comfort statements with baby tears or moss ball are in the middle of the foliage plant groups described above.

Compared to other visual stimulation conditions, the second-order coefficients of the regression coefficient for moss ball tend to differ from all of the others. Moss balls do not spread in a tree architecture, so even if we try to give them a high green coverage ratio, their psychological green coverage ratio may be recognized as relatively low.

We used a non-linear second-order regression model to verify homogeneity between conditions with no visual stimulation by foliage plants against conditions with foliage plants added. Comparing moss ball to the condition with no foliage plants in visual stimulation, we found that intercept, slope, and second order coefficient all have $\mathrm{p}<0.20$, showing significant differences.

Fondness for foliage plants may have effects, but it is possible that, if foliage plants with a coverage ratio approximately $0.75 \%$ or higher are placed on the side of the desk, then the thermal environment of an inorganic office working space may be organically improved to be more pleasant.

\subsection{Visual Stimulation and Human Responses}

Consistent with what Kurazumi et al. [14] point out, we also found that, due to the relationship between ETF and mean skin temperature, thermal stimulation has quantifiable physiological effects on the human body in mean skin temperature, but visual stimulation does not affect mean skin temperature. On the other hand, due to the relationship between ETF and mean skin temperature, when 
ETF is approximately $27^{\circ} \mathrm{C}$ to $29^{\circ} \mathrm{C}$, visual stimulation was found to have benefits that improve thermal sensations for thermal sensation statements. Also, when ETF is approximately $26^{\circ} \mathrm{C}$ to $29^{\circ} \mathrm{C}$, visual stimulation was found to have benefits that improve thermal comfort for comfort statements.

This benefit was significant when the green coverage ratio of foliage plants ranged from $0.75 \%$ to $4.67 \%$, which does not create a sense of crowding from the foliage plant. This research incorporates foliage plants as natural environment elements into personal space, with a relatively small distance between the body and the plants, so one can say there is a need to study crown architecture spreads that do not give a sense of crowding.

Kurazumi et al. [14] researched benefits that improve thermal senses due to green of plants that make people imagine outdoor spaces. In comparison, we found that, even with a low green coverage ratio, foliage plants have benefits that improve thermal senses in office work spaces. Our findings tend to indicate that, in an environmental range of temperatures that are slightly uncomfortable, people can be relieved by the benefit of presenting natural environment elements by foliage plants as visual stimulation, even in an office space with a high temperature setting of around $28^{\circ} \mathrm{C} \mathrm{ETF}$, which people would otherwise experience as slightly uncomfortable.

\section{Conclusions}

In Japan, as one of various actions to achieve a low-carbon society, in order to conserve energy, cut costs, and reduce greenhouse gas emissions, there is a push for behavior that reduces the energy expended on air conditioning by setting room temperature at $28^{\circ} \mathrm{C}$.

In contrast to the home, in the office it is difficult to use behavioral thermoregulation to improve heat exchange between the body and the environment. Thus we performed subjective experiments designed for office desktop spaces in environments with a temperature range that is slightly uncomfortable, with a high likelihood of forcing people to endure, and investigated the effects on comprehensive thermal senses of brain stimulation from the viewing of foliage plants.

Due to the relationship between ETF and thermal senses, when ETF was approximately $27^{\circ} \mathrm{C}$ to $29^{\circ} \mathrm{C}$, improvement in thermal sensation from the benefits of visual stimulation was shown. Also, when ETF was approximately $26^{\circ} \mathrm{C}$ to $29^{\circ} \mathrm{C}$, improvement in thermal comfort was also evident, again due to the benefits of visual stimulation. This benefit was significant when the green coverage ratio of foliage plants was between $0.75 \%$ and $4.67 \%$, which does not cause one to feel crowded or overwhelmed. This research incorporates foliage plants as natural environment elements into personal space, with a relatively short distance between the body and the plants, so one can say there is a need to study crown architecture spread that does not give a sense of crowding in the selection of foliage plants.

This suggests that, by incorporating the natural elements of foliage plants into 
office desktop environments, one can create environmentally friendly energy-conserving office spaces.

\section{Acknowledgements}

We would like to express our sincerest gratitude to the study subjects who participated in the present study.

\section{References}

[1] Wilson, E.O. (1984) Biophilia: The Human Bond with Other Species. Harvard University Press, Cambridge, MA.

[2] Kellert, S.R. and Wilson, E.O. (1993) The Biophilia Hypothesis. Island Press, Washington DC.

[3] Zajonc, R.B. (1980) Feeling and Thinking: Preferences Need No Inferences. American Psychologist, 35, 151-175. https://doi.org/10.1037/0003-066X.35.2.151

[4] Ulrich, R.S. (1984) View through a Window May Influence Recovery from Surgery. Science, 224, 420-421. https://doi.org/10.1126/science.6143402

[5] Rohles, F.H., Bennett, C.A. and Milliken, G.A. (1981) The Effects of Lighting, Color, and Room Décor on Thermal Comfort. ASHRAE Transactions, 87, 511-527.

[6] Matsubara, N., Ito, K., Kurazumi, Y., Gassho, A. and Nagano, K. (2000) Specific and Non-Specific Evaluation of the Combined Environment of Color and Temperature. Journal of Architecture, Planning and Environmental Engineering, 65, 39-45. https://doi.org/10.3130/aija.65.39_3

[7] Matsubara, N., Gassho, A., Kurazumi, Y., Sawashima, T. and Yamato, Y. (2004) Psychological Effects of the Visual Stimuli and the Auditory Stimuli on Thermal Sensation. Japanese Journal of Biometeorology, 40, 249-259.

[8] Murakami, D. and Shimomura, T. (2007) Examination of Comfort by the Thermal Environment Measurement and the Subjective Experiment on Three Different Parts of a Green Roof. Journal of the Japanese Society of Revegetation Technology, 33, $152-157$.

[9] Fukagawa, K., Kurazumi, Y., Yamato, Y., Tobita, K., Hase, H., Han, S., Oishi, H. and Cao, Z. (2010) The Effect of Visual Stimulus on Thermal Comfort: Analysis of the Visual Factor by Experiment. The 7 th International Cost Engineering Council World Congress \& The 14th Pacific Association of Quantity Surveyors Congress, 23-27 July 2010, Singapore, 1-10.

[10] Kurazumi, Y., Matsubara, N., Tsuchikawa, T., Kondo, E., Ishii, J., Fukagawa, K., Ando, Y., Yamato, Y., Tobita, K. and Horikoshi, T. (2011) Psychological Effects of the Environmental Stimuli on Thermal Sense in Outdoor Spaces. Japanese Journal of Biometeorology, 48, 129-144.

[11] Kurazumi, Y., Fukagawa, K., Yamato, Y., Tobita, K., Kondo, E., Tsuchikawa, T., Horikoshi, T. and Matsubara, N. (2011) Enhanced Conduction-Corrected Modified Effective Temperature as the Outdoor Thermal Environment Evaluation Index upon the Human Body. Building and Environment, 46, 12-21.

[12] Ministry of Education, Culture, Sports, Science and Technology, Government of Japan (2014).

http://www.mext.go.jp/b_menu/houdou/26/05/_icsFiles/afieldfile/2014/05/23/1348 $\underline{060 \_01 . p d f}$

[13] Ministry of the Environment, Government of Japan (2016).

http://www.env.go.jp/press/files/jp/27469.pdf 
[14] Kurazumi, Y., Fukagawa, K., Kondo, E. and Sakoi, T. (2014) Effects of Visual Stimuli upon Thermal Sense under Air Conditioning in Summer. Journal of Ergonomics, 4, 1-7.

[15] Kurazumi, Y., Tsuchikawa, T., Kondo, E., Horikoshi, T. and Matsubara, N. (2010) Conduction-Corrected Modified Effective Temperature as the Indices of Combined and Separate Effect of Environmental Factors on Sensational Temperature. Energy and Buildings, 42, 441-448.

[16] Kurazumi, Y., Tsuchikawa, T., Kondo, E., Yamato, Y., Tobita, K., Fukagawa, K., Horikoshi, T. and Matsubara, N. (2009) Validity and Evaluation Method of Combined Thermal Environmental Factors upon the Human Body. Japanese Journal of Biometeorology, 46, 121-137.

[17] Ministry of Health, Labour and Welfare in Japan (2016) The National Health and Nutrition Survey in Japan, 2013. http://www.mhlw.go.jp/bunya/kenkou/eiyou/dl/h25-houkoku-05.pdf

[18] Ministry of Health, Labour and Welfare in Japan (2016) The National Health and Nutrition Survey in Japan, 2014. http://www.mhlw.go.jp/bunya/kenkou/eiyou/dl/h26-houkoku-05.pdf

[19] Kurazumi, Y., Horikoshi, T., Tsuchikawa, T. and Matsubara, N. (1994) The Body Surface Area of Japanese. Japanese Journal of Biometeorology, 31, 5-29.

[20] World Medical Association (2016) WMA Declaration of Helsinki-Ethical Principles for Medical Research Involving Human Subjects.

https://www.wma.net/policies-post/wma-declaration-of-helsinki-ethical-principlesfor-medical-research-involving-human-subjects/

[21] Hanada, K., Mihira, K. and Ohhata, K. (1981) Studies on the Thermal Resistance of Women's Underwear. Journal of the Japan Research Association for Textile EndUse, 22, 430-437.

[22] Hanada, K., Mihira, K. and Sato, Y. (1983) Studies on the Thermal Resistance of Men's Underwear. Journal of the Japan Research Association for Textile End-Use, 24, 363-369.

[23] Kurazumi, Y., Tsuchikawa, T., Torii, T., Kakutani, K., Matsubara, N. and Horikoshi, T. (2004) Weighting Coefficients for Calculating Mean Skin Temperature When Considering Convective Heat Transfer Areas. Journal of the Human-Environment System, 7, 19-28. https://doi.org/10.1618/jhes.7.19

[24] Kurazumi, Y., Matsubara, N., Furukawa, N., Fujiwara, M., Ue, A., Ueki, Y., Nagai, H. and Yamamoto, S. (1998) Japanese Weighting Coefficients for Calculating Mean Skin Temperature in Relation to Posture. Japanese Journal of Biometeorology, 35, 121-132.

[25] Kurazumi, Y., Tsuchikawa, T., Matsubara, N. and Horikoshi, T. (2008) Effect of Posture on the Heat Transfer Areas of the Human Body. Building and Environment, 43, 1555-1565.

[26] Tsuchikawa, T., Kobayashi, Y., Horikoshi, T., Miwa, E., Kurazumi, Y. and Hirayama, K. (1988) The Effective Radiation Area of the Human Body and Configuration Factors between the Human Body and Rectangular Planes Measured by the Photographic Method. Measurement for Male Subjects; Four Combinations of Nude or Clothed and Standing or Sedentary Postures. Journal of Architecture, Planning and Environmental Engineering, 388, 48-59.

[27] Kurazumi, Y., Tsuchikawa, T., Ishii, J., Fukagawa, K., Yamato, Y. and Matsubara, N. (2008) Radiative and Convective Heat Transfer Coefficients of the Human Body in Natural Convection. Building and Environment, 43, 2142-2153. 
[28] Hendler, E., Crosbie, R. and Hardy, J.D. (1958) Measurement of Heating of the Skin during Exposure to Infrared Radiation. Journal of Applied Physiology, 12, 177-185.

[29] Kurazumi, Y., Sakoi, T., Tsuchikawa, T., Fukagawa, K., Bolashikov, Z.D. and Horikoshi, T. (2014) Behavioral Thermoregulation Model for Evaluation of Outdoor Thermal Environment. Journal of Ergonomics, 4, 1-14. https://doi.org/10.4172/2165-7556.1000125

[30] Kurazumi, Y., Tsuchikawa, T., Kondo, E., Ishii, J., Fukagawa, K., Yamato, Y., Tobita, K., Ando, Y., Matsubara, N. and Horikoshi, T. (2012) Thermal Comfort Zone in Outdoor Environment. Journal of Human and Living Environment, 19, 115-127.

[31] Shimada, R., Matsubara, N., Kurazumi, Y., Gassho, A. and Tobita, K. (2008) Difference of Scales on the Evaluation of the Experimental Combined Environment: Discussion with Attention. Journal of Environmental Engineering, 628, 807-813.

Submit or recommend next manuscript to SCIRP and we will provide best service for you:

Accepting pre-submission inquiries through Email, Facebook, LinkedIn, Twitter, etc. A wide selection of journals (inclusive of 9 subjects, more than 200 journals) Providing 24-hour high-quality service User-friendly online submission system Fair and swift peer-review system Efficient typesetting and proofreading procedure Display of the result of downloads and visits, as well as the number of cited articles Maximum dissemination of your research work

Submit your manuscript at: http://papersubmission.scirp.org/

Or contact health@scirp.org 